\title{
TITLE:
}

\section{Outcome of radial scar/complex sclerosing lesion associated with epithelial proliferations with atypia diagnosed on breast core biopsy - Results from a multicentric UK based study}

\section{Authors:}

Emad A Rakha ${ }^{1,7^{*}}$, Francisco Beca ${ }^{2 *}$ Mariangela D'Andrea ${ }^{3}$, Areeg Abbas ${ }^{1}$, William

Petrou-Nunn1, Abeer M Shaaban ${ }^{4}$, Aneeshya Kandiyil ${ }^{1}$, Samantha Smith ${ }^{5}$, Sindhu

Menon ${ }^{1}$, Somaia Elsheikh ${ }^{1,7}$, Maysa E EISayed ${ }^{7}$, Andrew H S Lee ${ }^{1}$, and Nisha Sharma ${ }^{6}$

*these authors contributed equally.

${ }^{1}$ Department of Histopathology, Nottingham University Hospitals NHS Trust, UK

${ }^{2}$ Department of Pathology, Stanford University School of Medicine, Stanford, CA, USA

${ }^{3}$ Specialization School in Anatomic Pathology, University of Pavia, Italy.

${ }^{4}$ Department of Cellular Pathology, Queen Elizabeth Hospital Birmingham and the University of Birmingham, UK

${ }^{5}$ South Birmingham Breast Unit, Queen Elizabeth Hospital Birmingham

${ }^{6}$ Department of Breast Radiology, St James's University Hospital, Leeds, UK.

${ }^{7}$ Faculty of Medicine, Menoufiya University, Egypt

\section{CORRESPONDING AUTHOR:}

Professor Emad Rakha

Department of Histopathology, Nottingham University Hospitals NHS Trust, City Hospital Campus, Hucknall Road, Nottingham, NG5 1PB, UK

Tel: (44) 0115-9691169

Fax: (44) 0115- 9627768

Email: emadrakha@yahoo.com

Emad.Rakha@nuh.nhs.uk

WORD COUNT: 2502

KEYWORDS: Breast core biopsy, B3, Radial scar, atypia, outcome. 


\section{ABSTRACT}

AIMS: The clinical significance of radial scar / complex sclerosing lesion (RS/CSL) with high risk lesions (epithelial atypia) diagnosed on needle core biopsy (NCB) is not well defined. We aimed at assessing the upgrade rate to carcinoma in-situ (DCIS) and invasive on the surgical excision specimen in a large cohort of RS/CSL associated with atypia.

METHODS: 161 women with NCB diagnosis of a RS/CSL with atypia and follow-up histology were studied. Histological findings including different forms of the atypical lesions and final histological outcome in the excision specimens were retrieved and analysed and the upgrade rate for malignancy and invasive carcinoma calculated.

RESULTS: $76 \%$ of the cases were associated with an atypical ductal hyperplasia (ADH) whereas lobular neoplasia was seen in $24 \%$. On final histology 38 cases were malignant (overall upgrade rate of 25\%); 12 invasive and 27 DCIS. The upgrade differed according to the type of atypia and was highest for ADH (35\%). When associated with lobular neoplasia the upgrade rate was $12 \%$. The upgrade rate's variability was also considerably lower and showing less variability when considering the upgrade to invasive carcinoma alone.

CONCLUSION: The upgrade rate for ADH diagnosed on NCB with RS is similar to that of ADH without RS and therefore should be managed similarly. RS associated with LN is less frequently associated with malignant outcome. Most lesions exhibiting some degree of atypia showed similar upgrade rate to invasive carcinoma. Management of RS should be based on the concurrent atypical lesion. 


\section{INTRODUCTION}

Radial scar (RS) and complex sclerosing lesion (RS/CSL), is a relatively uncommon benign lesion of the breast. RS/CSL usually consists of a central fibroelastotic core containing entrapped glandular structures with outwardly radiating, sometimes dilated ducts, creating a stellate appearance, with or without epithelial hyperplasia ${ }^{1}$. RS often presents radiologically as a spiculated mass or architectural distortion making it indistinguishable from invasive carcinoma by radiological appearances alone. As a result, needle core biopsy (NCB) is recommended for histological confirmation of suspected $\mathrm{RS}^{2}$.

The prevalence of RS/CSL diagnosis of NCB is approximately $1 \%^{3-6}$. Despite relatively rare, this is a lesion with important clinic-pathologic implications. Both diagnosis and management are still controversial. At low-power microscopy it may resemble an invasive carcinoma because of the lobular architecture disruption by the sclerosing process, thus presenting occasional diagnostic challenges especially in the absence of myoepithelial cell markers. In terms of management, the UK national guidelines recommend categorizing RS/CSL diagnosed on NCB as benign lesions of uncertain malignant potential (B3) lesion? Despite this recommendation, we and others have shown that the B3 group of lesions is heterogenous in terms of outcome, with a wide variation in the malignant upgrade rate ${ }^{8}$. In the specific case of RS/CSL this lesion comprises $8-32 \%$ of B3 lesions ${ }^{9-13}$ and large series with long follow-up have suggested that the apparent risk is related to the various patterns of associated intraductal proliferations rather than the presence of $\mathrm{RS} / \mathrm{CSL}^{14}$. Despite these findings, some authors have recommend surgical excision of RS/CSL regardless of any associated high risk intraductal proliferations (atypical ductal hyperplasia (ADH), atypical lobular hyperplasia, apocrine atypia, flat epithelial atypia (FEA), epithelial atypia of uncertain category and lobular neoplasia) ${ }^{5,6}$ and until recently surgical excision was the standard care $^{2,15}$. The current UK guidelines recommend vacuum-assisted excision with at least $4 \mathrm{~g}$ of tissue after an initial core biopsy or VAB diagnosis of RS/CSL with or without HRL ${ }^{16}$. 
However, only 15 to $40 \%$ of RS are associated with intraductal proliferations $11,12,17,18$. Therefore, we aimed to assess the upgrade rate to carcinoma in-situ and invasive on the surgical excision specimen in a cohort of RS/CSL with a combined atypia diagnosed on NCB. Additionally, we evaluated the associations between atypia type and patient's characteristics and the excision diagnosis in this cohort of patients.

\section{MATERIAL AND METHODS}

This was a retrospective multicentric study that includes 161 women who diagnosed with a RS/CSL with atypia. Involved institutions/breast units and patient accrual by institution were as follows: City Hospital, Nottingham University Hospitals, Nottingham, UK ( $n=53$ patients), Royal Derby Hospital, Derby, UK $(n=16)$, The Leeds Teaching Hospitals and Leeds/Wakefield Breast Screening Service, Leeds, UK ( $n=15)$, Queen Elizabeth Hospital, Birmingham UK $(n=5)$. Due to the rarity of this specific association we are studying, we also included, in the present cohort, data of patients with RSHR lesions collected from the breast screening units in the UK that our group has previously collected $(n=72)$.

All patients included in this cohort had a stellate lesion, mass or calcification on mammography and NCB that was reported as B3 with atypia according to UK guidelines. All of these cases were discussed at a multidisciplinary meeting with a breast radiologist, histopathologist and surgeon present, at which decisions were made on further appropriate therapeutic action. Histology reports of the NCB and/or vacuum assisted biopsy and the subsequent diagnostic biopsy results were reviewed by the local pathologist in each institution. RS not associated with any type of atypia or those associated with malignancy (ductal carcinoma in-situ (DCIS), invasive carcinoma or suspicious of invasive carcinoma) in the initial core biopsy were excluded. Only patients with RS associated with epithelial atypia were included in this study $(n=161)$. Data collected included patient age, radiological 
and clinical abnormalities, lesion size, core biopsy type and imaging technique (i.e., core or large bore vacuum assisted with guidance via ultrasound or stereotaxis). Details of the second line VAB and / or surgical excision, and the final diagnosis including histological details were also included.

The Nottingham breast pathology team centrally reviewed the surgical pathology reports for each case. Biopsy specimens were classified it according to the highest-grade lesion in one of the following categories of epithelial atypia: atypical ductal hyperplasia (ADH), flat epithelial atypia (FEA), atypical lobular hyperplasia/lobular carcinoma in-situ (ALH/LCIS), apocrine atypia ${ }^{19}$ and epithelial atypia of uncertain category (referred as "other atypia") which included lesions such as radial scar, biopsy site changes, fibrocystic changes or others. The final pathology results served as the reference standard and surgical excision histology findings were classified into 2 categories as follows: (i) malignant, including invasive carcinoma and ductal carcinoma in situ (DCIS), in addition to other malignant lesions such as sarcomas and lymphomas, and (ii) benign, for lesions including ADH and Lobular Neoplasia (ALH and LCIS). The association between the diagnosis on CNB and the outcome is reported as an upgrade rate or PPV for malignancy, calculated according to the European Guidelines for Quality Assurance in Breast Cancer Screening and Diagnosis (upgrade rate or PPV for malignancy $=$ number of malignant cases/total number of participants $\times 100)^{20}$. Other associations between parameters studied were evaluated using the $\mathrm{X} 2$ test or Fisher exact test, as appropriate. Statistical analyses were conducted data were analyzed using R Version 3.2.4 for Windows (64 bit) and a 2-tailed significance level of $5 \%$ was considered statistically significant. This study complies with the SQUIRE 2.0 (Standards for QUality Improvement Reporting Excellence) guidelines ${ }^{21}$. 


\section{RESULTS}

\section{Overall patients' characteristics}

Our series included 161 women diagnosed as radial scar with high risk lesions (RSHR) on first biopsy (either NCB or VAB). The mean age of women at first diagnosis was 58 years (range $30-77)$ and $19 \%(28 / 148)$ of the cases were symptomatic. The imaging abnormality was distortion (including a spiculate lesion/ stromal deformity) in $69.2 \%$, calcification in $21.5 \%$ and mass lesion in $9.2 \%$. Lesion size varied from $4 \mathrm{~mm}$ to $50 \mathrm{~mm}$ (mean size $17 \mathrm{~mm}$ ). Ultrasound guided biopsy was performed in $59 \%$ and stereotactic guided biopsy was performed in $41 \%$. Vacuum assisted biopsy (VAB) was the initial diagnostic procedure in 20 cases (14\%). Histological examination of the initial biopsy showed radial scar / complex sclerosing lesion with associated HRL (Table 1) and all cases were coded as B3 (Benign lesions of uncertain malignant potential). Atypical ductal hyperplasia (ADH) was the most common finding (38.8\%) followed by $32.2 \%$ with epithelial atypia of uncertain type (FEA and cytological or morphological atypia that cannot be fit in any of the other categories). Six cases showing more than one subtype of atypia (Figures 1-3). The high percentage of epithelial atypia of uncertain type was related to the lack of sub-classification of the type of atypia in the original reports; for instance, epithelial atypia, monotonous epithelial proliferation or with monotonous glands that failed to meet the criteria for FEA, ADH or lowgrade DCIS. Four cases showed changes similar to FEA but with nuclear pleomorphism more than expected in FEA but not sufficient for a definite diagnosis of DCIS. Five cases showed cytological atypia with minor degree of architecture atypia not sufficient for a definite diagnosis of $A D H$. Second line vacuum assisted biopsy ( $\left.2^{\text {nd }} V A B\right)$ was performed in 17 patients $(12 \%)$ whereas surgical excision was performed in 147 patients (data on type of excision specimen was missing in 4 patients and 3 patients had both $2^{\text {nd }} V A B$ and surgical excision). 


\section{Characteristics by surgical specimen diagnosis}

Patients characteristics by diagnosis type in the surgical specimen (benign vs malignant) are summarized in table 1 and were similar except for the referral type and core needle diagnosis.

A malignant outcome was more common in screening-detected lesions than in symptomatic patients or cases referrer for a consult $(p=0.036)$. Ninety percent of malignant cases were from the screening program with only $10 \%$ of cases associated with symptoms. On the other hand, most symptomatic cases were benign on final excision. Core needle diagnosis distribution was also different depending on the final diagnosis. Cases with ductal proliferations with atypia, in addition to the radial scar, in particular ADH and radial scars, were more often associated with a malignant outcome. Radial scars with areas of apocrine atypia, FEA or ALH/LCIS were only rare associated with a malignant outcome $(p=0.06)$

When stratifying the surgical specimen diagnosis, patient's characteristics displayed no significant differences between cases with DCIS or invasive carcinoma (summarized in table 2). Among the 27 cases with a final diagnosis of DCIS, 4 (19.0\%) were low grade and $7(33.3 \%)$ high grade with the remaining classifed as intermediate grade (47.6\%). Invasive carcinomas were predominantly low grade $(n=8)$ with only two cases with an intermediate grade and most were ductal NOS $(n=8,66.7 \%)$ with additional two cases of tubular carcinoma and two cases of invasive lobular carcinoma.

\section{Upgrade rates by initial core biopsy radial scar associated lesion}

The final diagnosis was malignant in 39 cases (12 invasive carcinomas) and benign in 119 cases, thus the overall upgrade rate for malignancy was $24.8 \%$ and $7.6 \%$ for invasive carcinoma only. Upgrade rates by core biopsy lesion type and final diagnosis can be found summarized in figure 1. Cases with RS associated with ADH displayed the highest upgrade grade to malignancy in our cohort (35\%). On the opposite end of the spectrum, cases of RS 
and FEA lesions were never upgrade and cases of RS with apocrine atypia were only upgrade to malignancy in $8.3 \%$ of cases. By comparison with previous published studies by our group and others using large cohorts of cases with radial scars, in the present cohort, cases of RS associated with FEA or apocrine atypia (less clear for ALH/LCIS) seem to display a lower upgrade rate to a malignant diagnosis than cases with isolated RS ( $9 \%$ for Rakha, $16 \%$ for mooney). Interestingly the differences in upgrade rates for invasive carcinoma was far less heterogenous than the upgrade rates for overall malignancy and displayed only slightly higher upgrade rates to cases with RS alone from studies used for comparison. Cases with RS and atypia where the specific classification of atypia and inclusion in a well-defined category was challenging, displayed upgrade rates of $26.53 \%$ for malignancy and of $12.24 \%$ for invasive carcinoma. The upgrade rates for overall malignancy is in between the upgrade for $\mathrm{ADH}$ and the other specific types of atypia included (both ductal/apocrine and lobular) and this upgrade rate for invasive carcinomas is the highest in this cohort. These finding reflect well the difficulty of classification of these lesions which display an heterogenous clinical outcome.

\section{DISCUSSION}

In this study we specifically investigated the outcome of atypia associated with RS on core needle biopsies. The overall upgrade rate for malignancy in the surgical specimen was $24.8 \%$ and was highly dependent on the type of atypia present in the CNB in association with the RS, with $A D H$ showing the highest upgrade rate and FEA and apocrine atypia showing negligible upgrade rates to malignancy.

While relatively specific, this is a common problem frequently found in busy breast pathology practices and reference centers for breast pathology. Previous studies have for the most part utilized smaller cohorts and meta-analysis type methods to investigate this 
specific question and have reported general upgrade rates for atypia without subclassification of the subtype of atypia, ${ }^{4,15,22,23}$. Even one of the largest studies of this type and to this date, by Mooney et al, has only included 25 patients with radial scars that had a surgical excision confirmed diagnosis ${ }^{3}$. In another, by Brenner et al, where only RS cases were included only 102 underwent surgical excision ${ }^{6}$. Therefore, our study is one of the largest multicentric series of patients with radial scars with associated atypia and surgical excision confirmed diagnosis. This fact has allowed us to report specific associations of types of atypia with RS and outcome on surgical excision. Despite the different methodologies and sample sizes, our reported upgrade rates for overall malignancy in the presence RS and any type of atypia is consistent with the previously reported rates of approximately $20-25 \%$ 4,15,22,23.

In this study the upgrade of RS for malignancy varied according to the type of atypia present. When RS was associated with ADH upgrade rate for malignancy was $35.0 \%$ and $6.7 \%$ for invasive carcinoma. This result is consistent with the upgrade rates for ADH in the absence of RS and therefore support the management of ADH with RS similar to ADH alone using second line $\mathrm{VAB}^{24}$ or surgical excision in case a less conservative approach is desired. For RS with FEA or apocrine atypia the combined upgrade rate for malignancy on final excision was $7.1 \%(2 / 14)$ with no cases diagnosed as an invasive carcinoma on final excision. For cases of RS association, with a lobular type atypia, either ALH or LCIS, the upgrade rate for malignancy $13.3 \%(4 / 30)$ with and even distribution between in situ and invasive carcinoma diagnosis on final excision. This upgrade rate for malignancy in the presence of RS and ALH/LCIS is lower than upgrade rates generally reported in literature for pure lesions, including by our group $4,13,25,26$. This fact may be explained by the impact of clinicopathological correlation in the cases included. If patients with radiological-pathological discordance or lobular neoplasia with necrosis or other risk lesions are excluded the risk may be very low ${ }^{8}$. It is possible that the low rate of malignancy in RS with lobular neoplasia 
in the present series is due a low rate of radiological-pathological discordance. Therefore, more studies of RS with lobular neoplasia including assessment of radiological-pathological discordance are needed to assess the risk in this group.

In our study while the upgrade rate to malignancy varied substantially, the variability of the upgrade rate to invasive carcinoma was generally low. When considering upgrade rate to invasive carcinoma, the variability among the several subtypes of atypia was low and comparable to RS lesions alone except in the case of atypia not otherwise classifiable or of difficult classification which displayed an upgrade rate to invasive carcinoma of $12.24 \%$ (6/49). Despite small number of cases seen as consults, none were upgraded to malignancy on final excision. While we recognized the difficulties that sometimes atypical lesions of the breast present in terms of specific classification, these findings once again suggest the importance of achieving proper classification of atypia either by $2^{\text {nd }}$ opinions or special consultations in particularly difficult cases $^{27}$. It also highlights the importance of the differential reporting of the upgrade rates for invasive carcinoma and not only for malignancy.

In conclusion, our study demonstrates that the specific subtype of atypical lesions in association with radial scar diagnosed on NCB is associated with a variable risk of malignancy, in particular, for carcinoma in-situ. While the upgrade rate for malignancy is similar in RS associated with ADH to pure ADH lesions, ALH/LCIS, FEA and apocrine atypia with associated RS seem to display a lower upgrade rate and further studies are needed to confirm this finding. Our study also highlighted the importance of the subclassification of the type of atypia present on a CNB, even when a RS is also diagnosed due to the significant upgrade rate to malignancy in these cases, especially for invasive carcinomas. 
CONFLICTS OF INTEREST: The authors declare no conflicts of interest.

\section{FUNDING:}

While not directly related to this work, FB is supported by the Department of Pathology of the Stanford University School of Medicine Pathology Trainee Mentored Award in Precision Health and Earlier.org - Friends for An Earlier Breast Cancer Test® Medical Research Grant. 


\section{REFERENCES}

1. Lakhani SR, Ellis I, Schnitt S, Tan P, van de Vijver M. WHO Classification of Tumours of the Breast. International Agency for Research on Cancer; 2012.

2. Miller CL, West JA, Bettini AC, et al. Surgical excision of radial scars diagnosed by core biopsy may help predict future risk of breast cancer. Breast Cancer Res Treat. 2014;145(2):331-338. doi:10.1007/s10549-014-2958-y

3. Mooney KL, Bassett LW, Apple SK. Upgrade rates of high-risk breast lesions diagnosed on core needle biopsy: a single-institution experience and literature review. Mod Pathol. 2016;29:1471. https://doi.org/10.1038/modpathol.2016.127.

4. Rakha EA, Lee AHS, Jenkins JA, Murphy AE, Hamilton LJ, Ellis IO. Characterization and outcome of breast needle core biopsy diagnoses of lesions of uncertain malignant potential (B3) in abnormalities detected by mammographic screening. Int $J$ cancer. 2011;129(6):1417-1424. doi:10.1002/ijc.25801

5. Osborn G, Wilton F, Stevens G, Vaughan-Williams E, Gower-Thomas K. A review of needle core biopsy diagnosed radial scars in the Welsh Breast Screening Programme. Ann R Coll Surg Engl. 2011;93(2):123-126. doi:10.1308/003588411X12851639107953

6. Brenner RJ, Jackman RJ, Parker SH, et al. Percutaneous core needle biopsy of radial scars of the breast: when is excision necessary? AJR Am J Roentgenol. 2002;179(5):1179-1184. doi:10.2214/ajr.179.5.1791179

7. Lee A (ed), Anderson N, Carder P, et al. Guidelines for Non-Operative Diagnostic Procedures and Reporting in Breast Cancer Screening. London, UK; 2016.

8. De Beça FF, Rasteiro C, Correia A, Costa S, Amendoeira I. Improved malignancy prediction by B3 breast lesions subclassification. Ann Diagn Pathol. 2013;17(5):434-436.

doi:10.1016/j.anndiagpath.2013.05.003

9. Saladin C, Haueisen H, Kampmann G, et al. Lesions with unclear malignant potential (B3) after minimally invasive breast biopsy: evaluation of vacuum biopsies performed in Switzerland and recommended further management. Acta Radiol. 2016;57(7):815-821.

doi:10.1177/0284185115610931

10. El-Sayed ME, Rakha EA, Reed J, Lee AHS, Evans AJ, Ellis IO. Predictive value of needle core biopsy diagnoses of lesions of uncertain malignant potential (B3) in abnormalities detected by mammographic screening. Histopathology. 2008;53(6):650-657. doi:10.1111/j.13652559.2008.03158.x

11. Dillon MF, McDermott EW, Hill AD, O'Doherty A, O'Higgins N, Quinn CM. Predictive value of breast lesions of "uncertain malignant potential" and "suspicious for malignancy" determined by needle core biopsy. Ann Surg Oncol. 2007;14(2):704-711. doi:10.1245/s10434-006-9212-8

12. Bianchi S, Giannotti E, Vanzi E, et al. Radial scar without associated atypical epithelial proliferation on image-guided 14-gauge needle core biopsy: analysis of 49 cases from a single-centre and review of the literature. Breast. 2012;21(2):159-164. doi:10.1016/j.breast.2011.09.005

13. Rageth CJ, O'Flynn EAM, Pinker K, et al. Second International Consensus Conference on lesions of uncertain malignant potential in the breast (B3 lesions). Breast Cancer Res Treat. November 2018. doi:10.1007/s10549-018-05071-1

14. Jacobs TW, Byrne C, Colditz G, Connolly JL, Schnitt SJ. Radial scars in benign breast-biopsy specimens and the risk of breast cancer. N Engl J Med. 1999;340(6):430-436. doi:10.1056/NEJM199902113400604

15. Linda A, Zuiani C, Furlan A, et al. Radial scars without atypia diagnosed at imaging-guided needle biopsy: how often is associated malignancy found at subsequent surgical excision, and do mammography and sonography predict which lesions are malignant? AJR Am J Roentgenol. 2010;194(4):1146-1151. doi:10.2214/AJR.09.2326

16. Programme. NBS. Clinical Guidance for Breast Cancer Screening Assessment. London, UK; 2016.

17. Li Z, Ranade A, Zhao C. Pathologic findings of follow-up surgical excision for radial scar on breast core needle biopsy. Hum Pathol. 2016;48:76-80. doi:10.1016/j.humpath.2015.06.028 
18. Donaldson AR, Sieck L, Booth CN, Calhoun BC. Radial scars diagnosed on breast core biopsy: Frequency of atypia and carcinoma on excision and implications for management. Breast. 2016;30:201-207. doi:10.1016/j.breast.2016.06.007

19. O'Malley FP, Bane AL. The spectrum of apocrine lesions of the breast. Adv Anat Pathol. 2004;11(1):1-9. http://www.ncbi.nlm.nih.gov/pubmed/14676636.

20. Perry N, Broeders M, de Wolf C, Törnberg S, Holland R, von Karsa L. European Guidelines for Quality Assurance in Breast Cancer Screening and Diagnosis. 4th ed. Luxembourg City, Luxembourg: European Commission; 2006. http://ec.europa.eu/health/ph_projects/2002/cancer/fp_cancer_2002_ext_guid_01.pdf.

21. Ogrinc G, Davies L, Goodman D, Batalden P, Davidoff F, Stevens D. SQUIRE 2.0-Standards for Quality Improvement Reporting Excellence-Revised Publication Guidelines from a Detailed Consensus Process. J Am Coll Surg. 2016;222(3):317-323. doi:10.1016/j.jamcollsurg.2015.07.456

22. Conlon N, D'Arcy C, Kaplan JB, et al. Radial Scar at Image-guided Needle Biopsy: Is Excision Necessary? Am J Surg Pathol. 2015;39(6):779-785. doi:10.1097/PAS.0000000000000393

23. Leong RY, Kohli MK, Zeizafoun N, Liang A, Tartter PI. Radial Scar at Percutaneous Breast Biopsy That Does Not Require Surgery. J Am Coll Surg. 2016;223(5):712-716. doi:10.1016/j.jamcollsurg.2016.08.003

24. Strachan C, Horgan K, Millican-Slater RA, Shaaban AM, Sharma N. Outcome of a new patient pathway for managing B3 breast lesions by vacuum-assisted biopsy: time to change current UK practice? J Clin Pathol. 2016;69(3):248-254. doi:10.1136/jclinpath-2015-203018

25. Menon S, Porter GJR, Evans AJ, et al. The significance of lobular neoplasia on needle core biopsy of the breast. Virchows Arch. 2008;452(5):473-479. doi:10.1007/s00428-008-0607-8

26. Murray MP, Luedtke C, Liberman L, Nehhozina T, Akram M, Brogi E. Classic lobular carcinoma in situ and atypical lobular hyperplasia at percutaneous breast core biopsy: outcomes of prospective excision. Cancer. 2013;119(5):1073-1079. doi:10.1002/cncr.27841

27. Elmore JG, Longton GM, Carney PA, et al. Diagnostic concordance among pathologists interpreting breast biopsy specimens. JAMA. 2015;313(11):1122-1132. doi:10.1001/jama.2015.1405 


\section{Tables}

Table 1. Patients' characteristics according to final diagnosis

\begin{tabular}{|c|c|c|c|}
\hline \multirow[b]{2}{*}{ Patients Characteristics } & \multicolumn{2}{|c|}{ Final Diagnosis } & \multirow[b]{2}{*}{ p-value } \\
\hline & Benign & Malignant & \\
\hline Number of patients (\%) & 118 & 39 & \\
\hline $\begin{array}{l}\text { Origin }(\%) \\
\text { Birmingham } \\
\text { Derby } \\
\text { Leeds } \\
\text { Nottingham } \\
\text { Other/Screening program }\end{array}$ & $\begin{array}{c}5(4.2) \\
11(9.3) \\
13(11.0) \\
41(34.7 \\
48(40.7)\end{array}$ & $\begin{array}{c}0(0.0) \\
4(10.3) \\
2(5.1) \\
9(23.1) \\
24(61.5)\end{array}$ & 0.148 \\
\hline Age (mean (SD) & $57.44(8.72)$ & $59.52(8.12)$ & 0.232 \\
\hline $\begin{array}{l}\text { Imaging abnormality (\%) } \\
\text { Calcification } \\
\text { Distortion } \\
\text { Mass }\end{array}$ & $\begin{array}{c}10(21.7) \\
33(71.7) \\
3(6.5)\end{array}$ & $\begin{array}{c}4(21.1) \\
12(63.2) \\
3(15.8)\end{array}$ & 0.497 \\
\hline Lesion size in $\mathrm{mm}$ (mean (SD) & $17.53(10.49)$ & $20.67(20.03)$ & 0.649 \\
\hline $\begin{array}{l}\text { Referral type } \\
\text { Screening } \\
\text { Symptomatic patient } \\
\text { Consult cases }\end{array}$ & $\begin{array}{c}81(70.4) \\
24(20.9) \\
10(8.7)\end{array}$ & $\begin{array}{c}35(89.7) \\
4(10.3) \\
0(0.0)\end{array}$ & 0.036 \\
\hline $\begin{array}{l}\text { Biopsy guidance method } \\
\text { Stereotaxic } \\
\text { US }\end{array}$ & $\begin{array}{l}34(39.1) \\
52(59.8)\end{array}$ & $\begin{array}{l}13(44.8) \\
15(51.7)\end{array}$ & 0.673 \\
\hline $\begin{array}{l}\text { Biopsy type } \\
\text { Conventional } \\
\text { Vacuum-assisted }\end{array}$ & $\begin{array}{l}87(82.3) \\
18(17.1)\end{array}$ & $\begin{array}{c}34(91.9) \\
3(8.1)\end{array}$ & 0.288 \\
\hline $\begin{array}{l}\text { Second line Vacuum-assisted } \\
\text { Yes } \\
\text { No }\end{array}$ & $\begin{array}{l}15(14.9) \\
86(85.1)\end{array}$ & $\begin{array}{c}2(5.1) \\
37(94.9)\end{array}$ & 0.197 \\
\hline $\begin{array}{l}\text { Core Biopsy Diagnosis } \\
\text { ADH } \\
\text { Apocrine atypia } \\
\text { ALH/LCIS } \\
\text { FEA } \\
\text { Other atypia }\end{array}$ & $\begin{array}{c}39(33.1) \\
11(9.3) \\
30(25.4) \\
2(1.7) \\
36(30.5)\end{array}$ & $\begin{aligned} 21 & (53.8) \\
1 & (2.6) \\
4 & (10.3) \\
0 & (0.0) \\
13 & (33.3)\end{aligned}$ & 0.063 \\
\hline
\end{tabular}

Percentages for categorial variables are relative to the row total.

"Other atypia" category includes lesions such as radial scar, biopsy site changes, fibrocystic changes or others. 
Table 2. Patients' characteristics with malignant final diagnosis

Final Diagnosis

\begin{tabular}{|c|c|c|c|}
\hline Patients Characteristics & In-situ & Invasive & p-value \\
\hline Number of patients (\%) & 27 & 12 & \\
\hline $\begin{array}{l}\text { Origin }(\%) \\
\text { Birmingham } \\
\text { Derby } \\
\text { Leeds } \\
\text { Nottingham } \\
\text { Other/Screening program }\end{array}$ & $\begin{array}{c}0(0.0) \\
3(11.1) \\
2(7.4) \\
8(29.6) \\
14(51.9)\end{array}$ & $\begin{array}{c}0(0.0) \\
1(8.3) \\
0(0.0) \\
1(8.3) \\
10(83.3)\end{array}$ & 0.270 \\
\hline Age (mean (SD) & $58.0(8.29)$ & $62.17(7.42)$ & 0.160 \\
\hline $\begin{array}{l}\text { Imaging abnormality (\%) } \\
\text { Calcification } \\
\text { Distortion } \\
\text { Mass }\end{array}$ & $\begin{array}{l}1(9.1) \\
8(72.7) \\
2(18.2)\end{array}$ & $\begin{array}{l}3(37.5) \\
4(50.0) \\
1(12.5)\end{array}$ & 0.325 \\
\hline Lesion size in mm (mean (SD) & $17.53(10.49)$ & $20.67(20.03$ & 0.649 \\
\hline $\begin{array}{l}\text { Referral type } \\
\text { Screening } \\
\text { Symptomatic patient }\end{array}$ & $\begin{array}{c}23(85.2) \\
4(14.8)\end{array}$ & $\begin{array}{c}12(100.0 \\
0(0.0)\end{array}$ & 0.403 \\
\hline $\begin{array}{l}\text { Biopsy guidance method } \\
\text { Stereotaxic } \\
\text { US }\end{array}$ & $\begin{array}{l}11(52.4) \\
10(47.6)\end{array}$ & $\begin{array}{l}2(28.6) \\
5(71.4)\end{array}$ & 0.512 \\
\hline $\begin{array}{l}\text { Biopsy type } \\
\text { Conventional } \\
\text { Vacuum-assisted }\end{array}$ & $\begin{array}{c}23(92.0) \\
2(8.0)\end{array}$ & $\begin{array}{c}11(91.7) \\
1(8.3)\end{array}$ & 1.00 \\
\hline $\begin{array}{l}\text { Second line Vacuum-assisted } \\
\text { Yes } \\
\text { No }\end{array}$ & $\begin{array}{c}2(7.4) \\
25(92.6)\end{array}$ & $\begin{array}{c}0(0.0) \\
12(100.0)\end{array}$ & 0.856 \\
\hline $\begin{array}{l}\text { Core Biopsy Diagnosis } \\
\text { ADH } \\
\text { Apocrine atypia } \\
\text { ALH/LCIS } \\
\text { Other atypia }\end{array}$ & $\begin{aligned} & 17(63.0) \\
& 1(3.7) \\
& 2(7.4) \\
& 7(25.9) \\
&\end{aligned}$ & $\begin{array}{l}4(33.3) \\
0(0.0) \\
2(16.7) \\
6(50.0)\end{array}$ & 0.268 \\
\hline
\end{tabular}

Percentages for categorial variables are relative to the row total.

Other atypia" category includes lesions such as radial scar, biopsy site changes, fibrocystic changes or others. 
bioRxiv preprint doi: https://doi.org/10.1101/538330; this version posted February 4, 2019. The copyright holder for this preprint (which was not certified by peer review) is the author/funder, who has granted bioRxiv a license to display the preprint in perpetuity. It is made available under aCC-BY-NC-ND 4.0 International license.

\section{Figures}

\section{Figure 1}
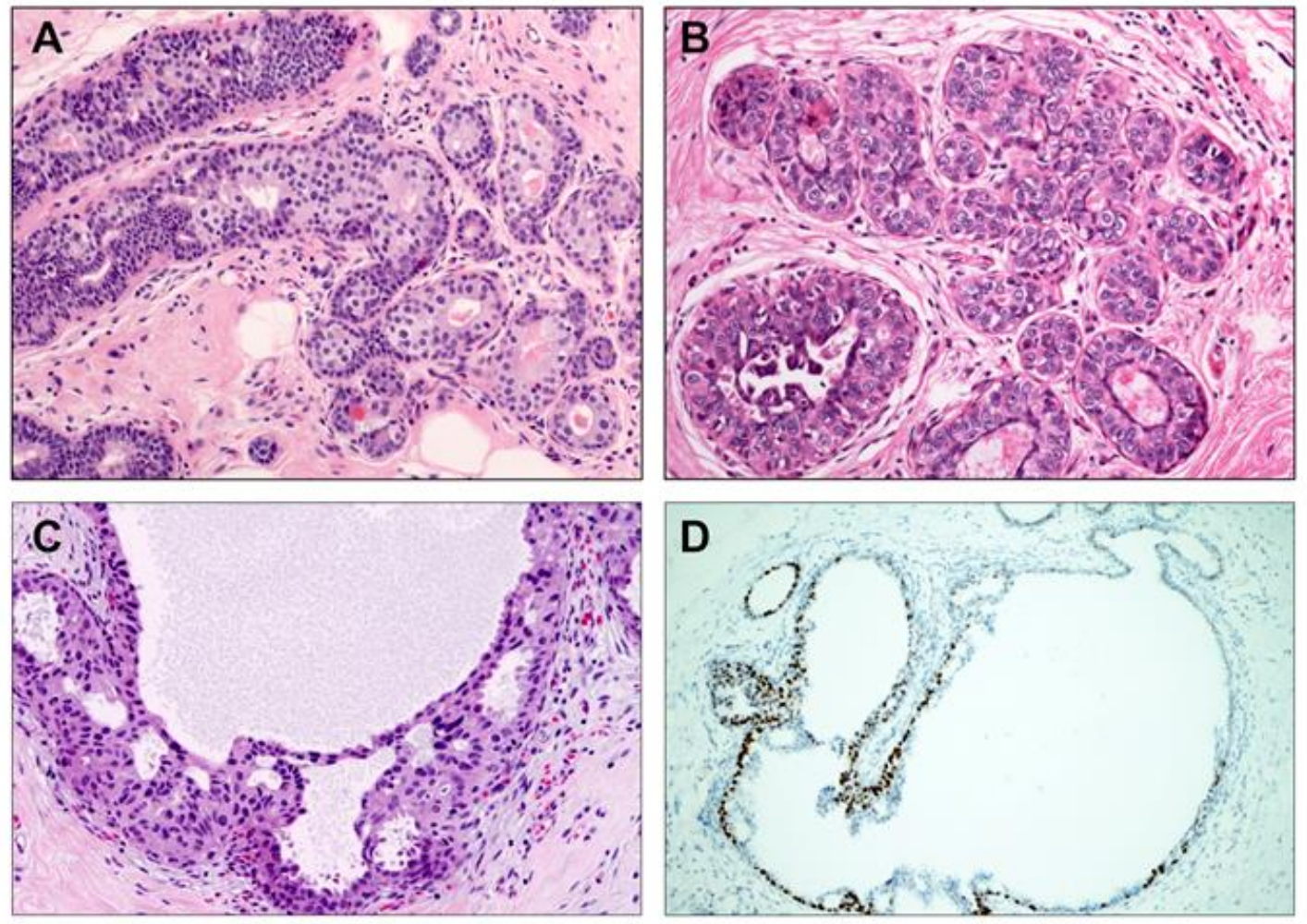
bioRxiv preprint doi: https://doi.org/10.1101/538330; this version posted February 4, 2019. The copyright holder for this preprint (which was not certified by peer review) is the author/funder, who has granted bioRxiv a license to display the preprint in perpetuity. It is made available under aCC-BY-NC-ND 4.0 International license.

\section{Figure 2}

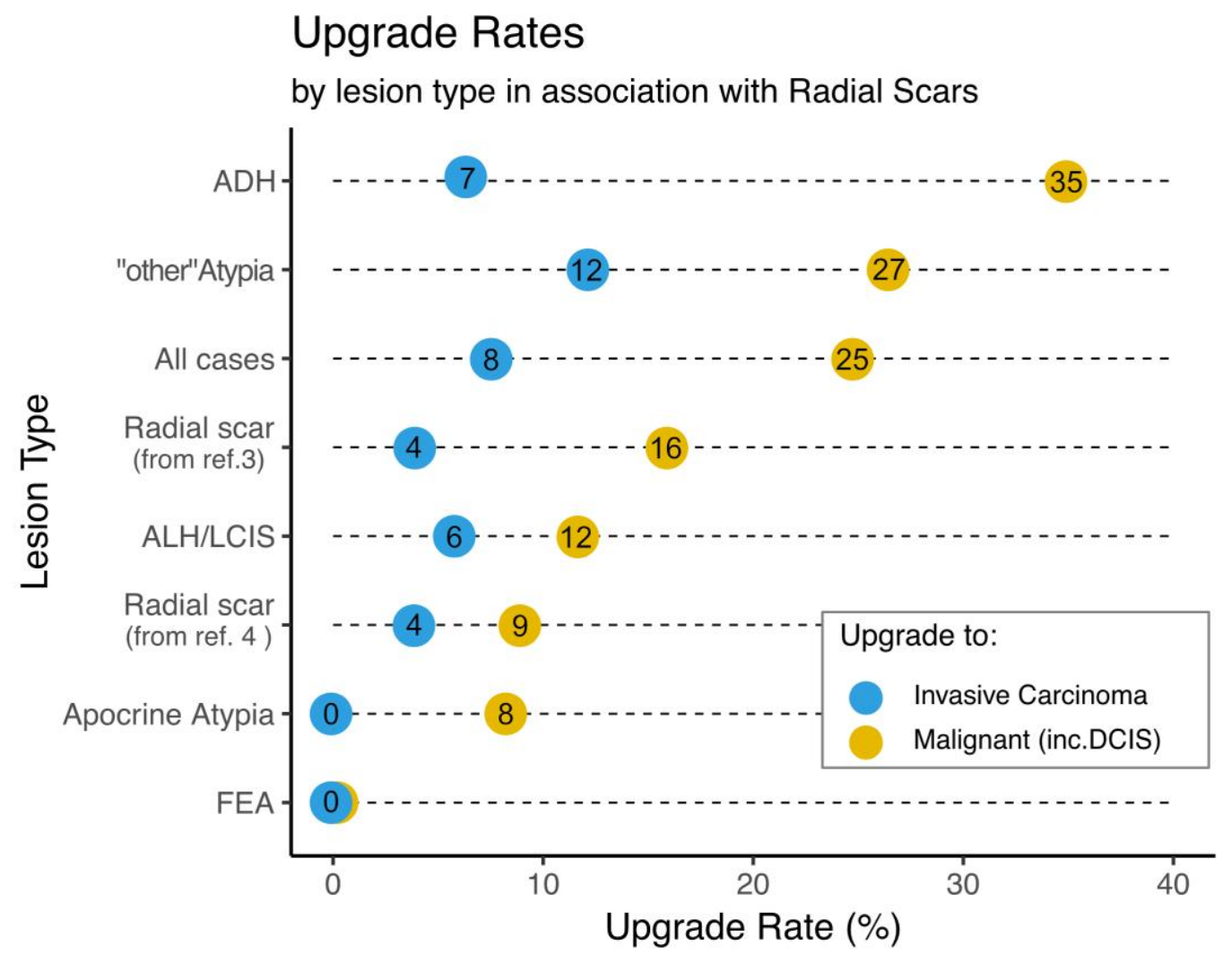




\section{Figure legends}

Figure 1: (A) Atypia not otherwise specified, E-cadherin positive but no typical of FEA or ADH (H\&E, 100x); (B) Terminal duct-lobular unit involved by atypical cells not sufficient for B5a (malignant in situ) diagnosis. E-cadherin immunostaining is positive. Surgical specimen showed DCIS with cancerization of lobules (H\&E, 200x); (C) A case of atypical intraductal epithelial proliferation (AIDEP) featuring cytological atypia and mild architecture atypia (H\&E, 100x) (D) oestrogen receptor (ER) staining shows patchy nuclear staining (ER, 40x).

Figure 2: Upgrade rates to malignancy and invasive carcinoma by lesion type. Upgrade rates are expressed as a percentage and the values rounded to the unit. 